\title{
COMPARATIVE STUDY OF FAULT LOCATION METHODS FOR RADIAL DISTRIBUTION SYSTEMS
}

\author{
A. I. Taalab, H. A. Darwish \\ Faculty of Engineering. \\ Menoufiya University, \\ Shebin El-Kom, EGYPT \\ M. A. Elkhazendar, G. E. M. Aly, M. A. Alam \\ Faculty of Engineering, \\ Tanta University, \\ Tanta, EGYPT'
}

\begin{abstract}
In this paper, a comparative study among various fault location techniques used for radial distribution feeders is presented. In these techniques the three-phase fundamental current and voltage phasors at the relaying point are used to compute the fault location. This computation is based on simulating an actual rural distribution feeder using the Electromagnetic Transient Program (EMTP). The effect of intermediate loads, fault resistance, and the fault type and location on the accuracy of fault location determination is investigated. Applicability of each of the techniques to on-line application is examined. The results revealed the most appropriate technique among the compared fault location techniques.
\end{abstract}

Keywords: Fault location techniques. DFT. LMTP simulation. Computer relaying

\section{INTRODUCTION}

Electric power systems are designed to ensure a reliable supply of energy with the highest possible continuity. Incident fault and simultaneous operation of protective relays may result in service interruption at the consumer terminals. Therefore, accurate determination of the fault location is recommended for further fast repairing of the fault to restore the system power.

Fault location in distribution networks in particular represents a sophisticated problem. This is because distribution feeders usually contain laterals and sub-laterals as with the aerial lines. Thus, different locations of the fault can produce the same fault symptoms seen at the remote end of the feeder.

Fault location techniques in distribution system depend on the type of feeding. Distribution feeders may be either fed from one end or fed from both ends. For feeders fed from one end, there are several fault location techniques have been reported. These can be classified mainly to conventional and artificial intelligent techniques. Four conventional techniques are compared in this paper. The first method is designated by the apparent impedance method 
depending on the type of fault, is calculated to determine the distance to the fault. The second method is designated by automated fault location and diagnosis [2], in this method the recorded data at the relaying point is used to calculated the fault distance and fault locations at various laterals via their scenarios. Also, in this method, the inequalities of mutual coupling between phases can be taken into consideration. The third method is based on the reactive power flow [3], in which a selected phase or phases reactive power, depending on the type of fault, is divided by this particular phase or phases reactive power per unit length. In the fourth method updating current and voltage vectors with static load [1] are used to calculate the fault location with elimination of the effect load flow.

There are other techniques for feeder fed from two ends or for multi-infeed feeders such as Global Position Satellite (GPS) [4], synchronized data and unsynchronized data method [5], and method depends on Artificial Neural Networks ANNs [6].

In this paper, a comparative study among four fault location methods applied to a specific field medium voltage radial distribution feeder fed from one end is given. The comparison is carried out from the view point of accuracy, speed in determining the fault location and the ability of on-line application. Also, the effects of load current flow, fault distance from the source, system topology, fault resistance on the error of determining the locations for each method are investigated. The result will aid the field engineers to evaluate and select the most appropriate and accurate method for his own application. The specific feeder system used for this study is first simulated using EMTP as given below.

\section{Simulated System}

Feeder system used in this study is a typical medium voltage distribution feeder in Egyptian distribution network. This feeder is shown in Fig.1, in which the bus-coupler CB5 and isolator switch S1 are normally open. It is closed upon outages of one of main transformers. The locations of the distribution transformers along the feeder are as shown. The ratings of the transformers and other relevant parameters are as given in the appendix. In simulating this feeder the EMTP source type 14 is used and the PI-circuit branch representation is considered. The fault simulation was carried out for line-to-line and line-to-ground faults at equispace of 100 meters distant along the feeder, with normal operation (i.e. switch S1 and bus-coupler CB5 are open). This is carried out also with switch S1 closed and CB5 open which represent the worst condition as far as fault location is concerned. In the forgoing applications of the four fault location methods, the worst condition is considered.

Fault location is calculated from CB1 point to the fault point for each fault location methods compared. Samples of three-phase voltages and currents are given by EMTP simulation. The output of EMTP simulation is used as an input to a recursive discrete Fourier transform filters (DFTs) [7]. The output of these DFT represent the voltage and current signals at the relaying point. These 
signals are used by the fault locator to compute the distance of the fault from the relaying point.

The algorithm of computation depends on the technique used as given in the subsequent sections.

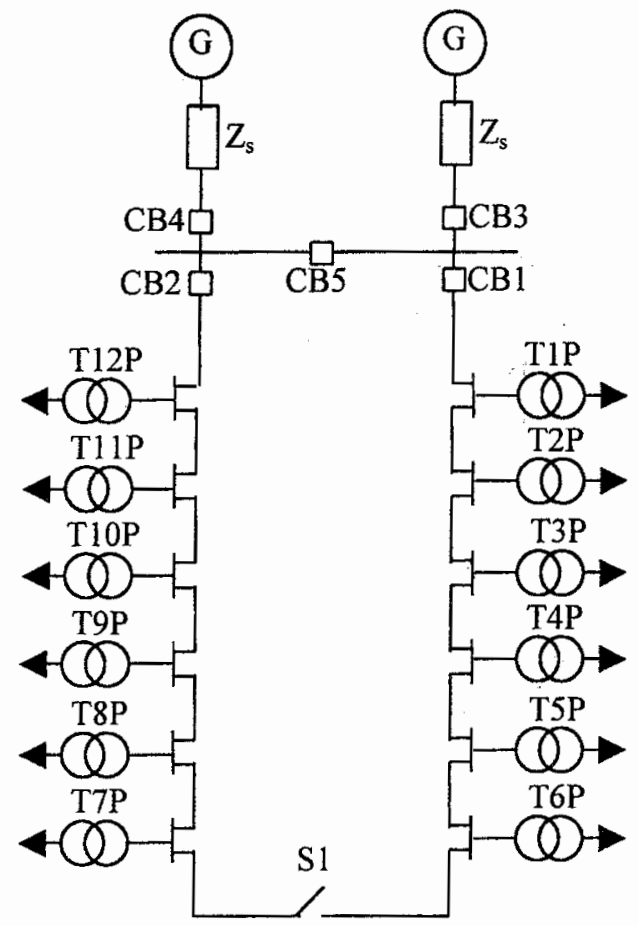

Fig. 1 Single line diagram of simulated system

\section{APPARENT IMPEDANCE METHOD}

Apparent impedance seen by this fault locator is defined as the ratio between a selected voltage and a selected current phasors at CB1. this impedance represents the impedance from the $\mathrm{CB} 1$ point to the fault point and can be calculated as

$$
Z_{\text {app }}=\frac{V_{\text {select }}}{I_{\text {select }}}=\left(r_{1}+j x_{1}\right) D_{c}+\frac{I_{\text {comp }}}{I_{\text {select }}} R_{f}
$$

where

$Z_{\text {app }}$ is the apparent impedance from the $\mathrm{CB} 1$ point to the fault point

$D_{c}$ is the computed distance from the relay point to the fault point

$r_{1}$ and $x_{1}$ are the positive sequence resistance and reactance per unit length

$\mathrm{V}_{\text {select }}$ is the selected voltage

$\mathrm{I}_{\text {select }}$ is the selected current

$I_{\text {comp }}$ is the compensated current

The appropriate selected voltage and selected current phasors depends on the type of fault. For line-to-line faults, the selected voltage is the voltage difference of the two faulted phases and the selected current is the current difference of the two faulted phases (i.e. for line $A$-to-line $B$ fault $V_{\text {select }}=V_{a}-$ 


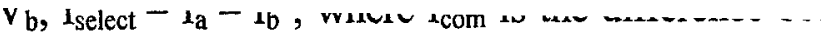

in line $A$ and in line $B$ due to fault. Double line to ground and three-phase faults are the same as line-to-line faults. However, for ground fault, the selected voltage is the voltage of the faulted phase and the selected current will be the faulted phase current in addition to a compensating factor (i.e. for line A-toground fault $V_{\text {select }}=V_{a}, I_{\text {select }}=I_{a}+k I_{0}$, and $I_{\text {comp }}=3 I_{0}$ where $k I_{0}$ is the compensating factor. This factor is to compensate for the effect of the fault resistance.

The percentage error of the fault location is computed at different points along the feeder, different values of fault resistance and at different loading conditions. In Fig.2a the percentage error is plotted against fault point distance for line-to-line fault with fault resistance $R_{f}$ of 0,10 , and $20 \mathrm{Ohms}$. It can be seen that, with solid fault $\left(R_{f}=0 \mathrm{Ohm}\right)$, as the fault point is moved towards the end of the feeder the error is increased to about $-7 \%$. Also, for $R_{f}=10 \mathrm{Ohm}$ the error is increased at first towards a positive value of $5 \%$ then reduces to zero at the middle of the feeder. The error is increased again in the negative sense towards $-8 \%$ at the end of the feeder. For $R_{f}=20 \mathrm{Ohm}$, a similar pattern to the case of $R_{f}=10 \mathrm{Ohm}$ is obtain, but with higher values of error along the feeder. This result shows the significant effect of the position of fault along the feeder and the value of fault resistance on the fault locator estimation with this method.

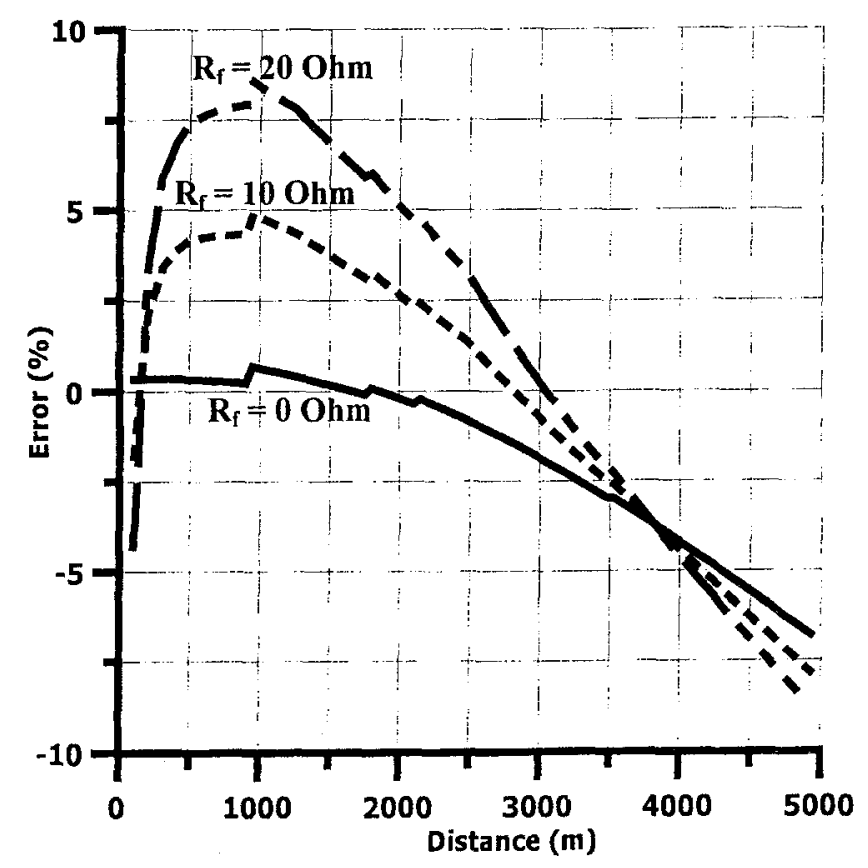

Fig.2a Fault location error along the feeder for different values of fault resistance for line-to-line fault with the first method. 
The effect of load flow is examined with solid fault $\left(\mathrm{R}_{\mathrm{f}}=0 \mathrm{Ohm}\right)$ for line-toline fault and the results are plotted as shown in Fig.2b. It can be seen that as the load flow increases as the fault location error increases. The maximum error occurs at the end of the feeder at full-load of about $-7 \%$. On the other hand at no-load the error is almost steady along the feeder to a less than $+1 \%$ regardless of the value of fault resistance.

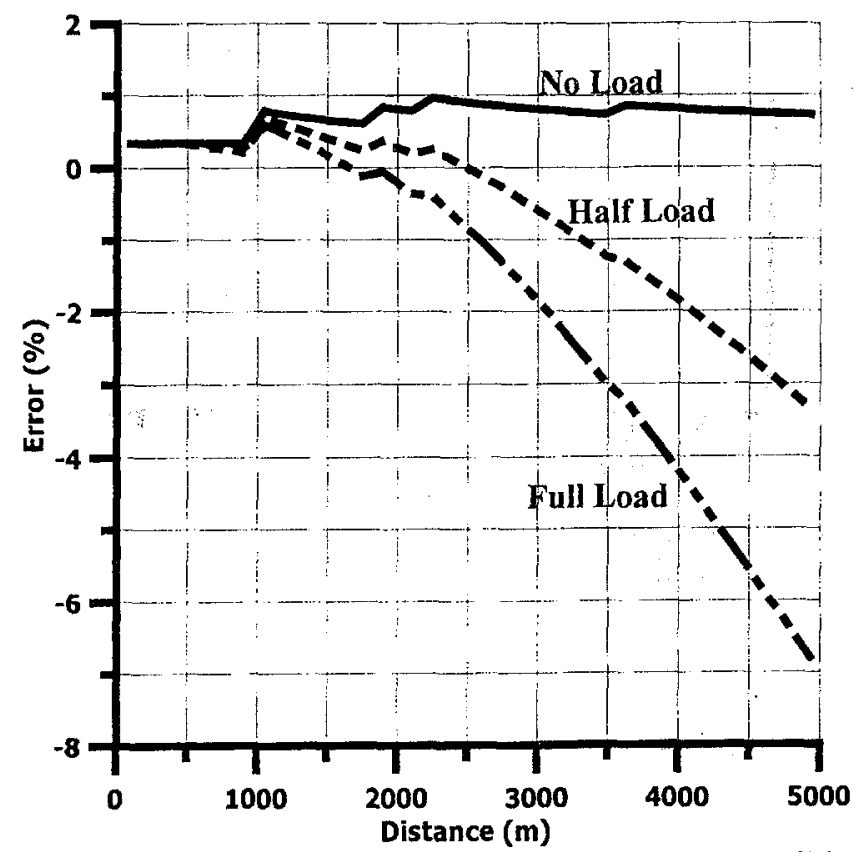

Fig.2b Fault location error along the feeder with different loading condition for line-to-line fault with the first method.

In Fig. 3 the effect of same values of fault resistance on the error for line-toground fault is shown. It can be seen that, as the fault point is increased towards the end of the feeder the error proportionally increases to its maximum value (in the negative sense) at the end of the feeder. This pattern is obtained for all values of fault resistance. However, for the three values of fault resistance considered, the maximum error is obtained at the highest value of fault resistance $\left(\mathrm{R}_{\mathrm{f}}=20 \mathrm{Ohm}\right)$ about $-13.5 \%$. The effect of loading condition on the percentage of fault location error for line-to-ground fault is computed and in which the error also increases as the initial load flow increases. The maximum error also occurs at the end of the feeder of about $-8.5 \%$ at full-load.

\section{Automated Fault Location Method}

In this method, distance to the fault point can be calculated using voltage and current phasors estimated at CB1 considering the effect of self and mutual impedances of the feeder, load type, and the fault type. Assuming equal self impedance and mutual impedance between phases, static load and line-to-line fault, distance to the fault point is computed, for phases a and b, from Eq.(2) as: 


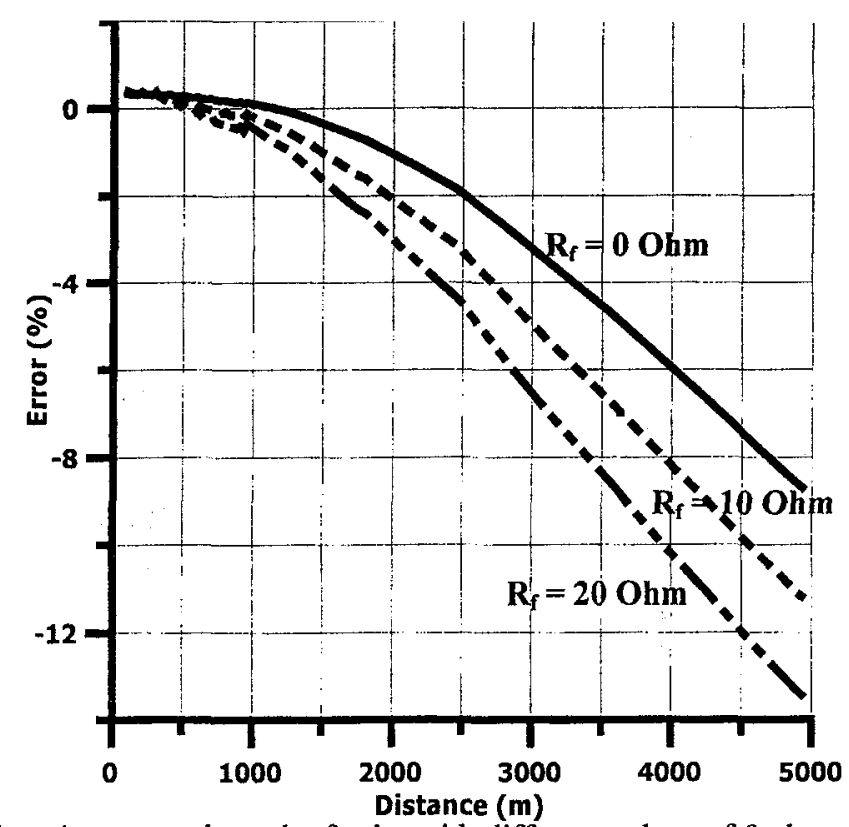

Fig. 3 Fault location error along the feeder with different values of fault resistance for lineto-ground fault with the first method

$$
V_{a}-V_{b}=D\left(z_{s}-z_{m}\right)\left(I_{a}-I_{b}\right)+\left(\Delta I_{a}-\Delta I_{b}\right) R_{f}
$$

However for line-to-ground fault on phase a, fault distance is calculated from Eq.(3) as:

$$
V_{a}=D\left(z_{s} I_{a}+z_{m} I_{b}+z_{m} I_{c}\right)+I_{f} R_{f}
$$

where

$\mathrm{D}$ is the distance from CB1 to the fault point.

$\mathrm{Z}_{\mathrm{s}}$ is the self impedance.

$\mathrm{z}_{\mathrm{m}}$ is the mutual impedance.

$\mathrm{R}_{\mathrm{f}}$ is the fault resistance.

$\Delta \mathrm{I}_{\mathrm{a}}$ and $\Delta \mathrm{I}_{\mathrm{b}}$ are the superimposed current in phase $\mathrm{A}$ and phase $\mathrm{B}$ respectively.

$I_{f}$ is the fault current.

The fault error was calculated along the feeder for $R_{f}=0,10$ and $20 \mathrm{Ohms}$ at full loading condition for line-to-line and line-to-ground faults. The results are plotted as shown in Fig.4a for line-to-line fault and in Fig.4b for line-to-ground fault. It can be seen that the error variation along the feeder, for line-to-line fault, has almost a similar pattern to the first method. However, the maximum positive error is at $R_{f}=20 \mathrm{Ohms}$ is about $+7.0 \%$ compared with about $+8.5 \%$ with the first method. The maximum errors at the feeder end has almost the same values of positive error as the first method. However, the pattern for lineto-ground fault is changed as shown in Fig. $4 b$. in this figure, as $R_{f}$ increases the percentage error increases and swings from positive to negative. It yields higher error than in the first method by values of about $+4.0 \%$ and $-2.0 \%$ at $R_{f}$ $=20 \mathrm{Ohms}$. 
The initial load flow effect for line-to-line with solid fault is shown in Fig.5. It can be seen that the second method is affected by the initial load flow in a - similar pattern to the first method.

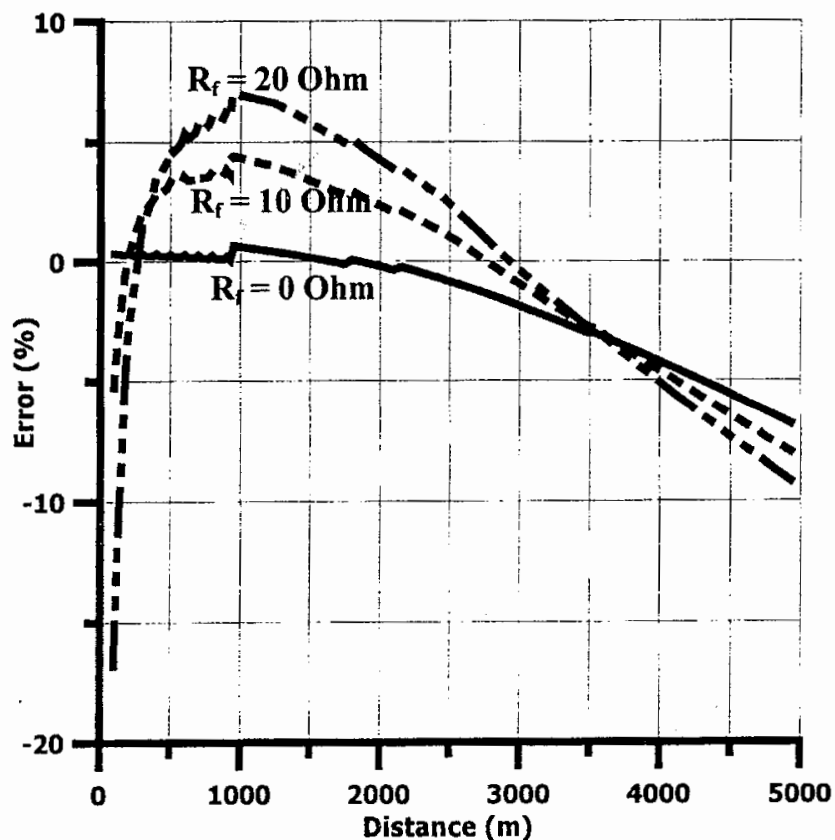

Fig.4a Fault location error along the feeder for line-to-line fault with different values of fault resistance with the second method

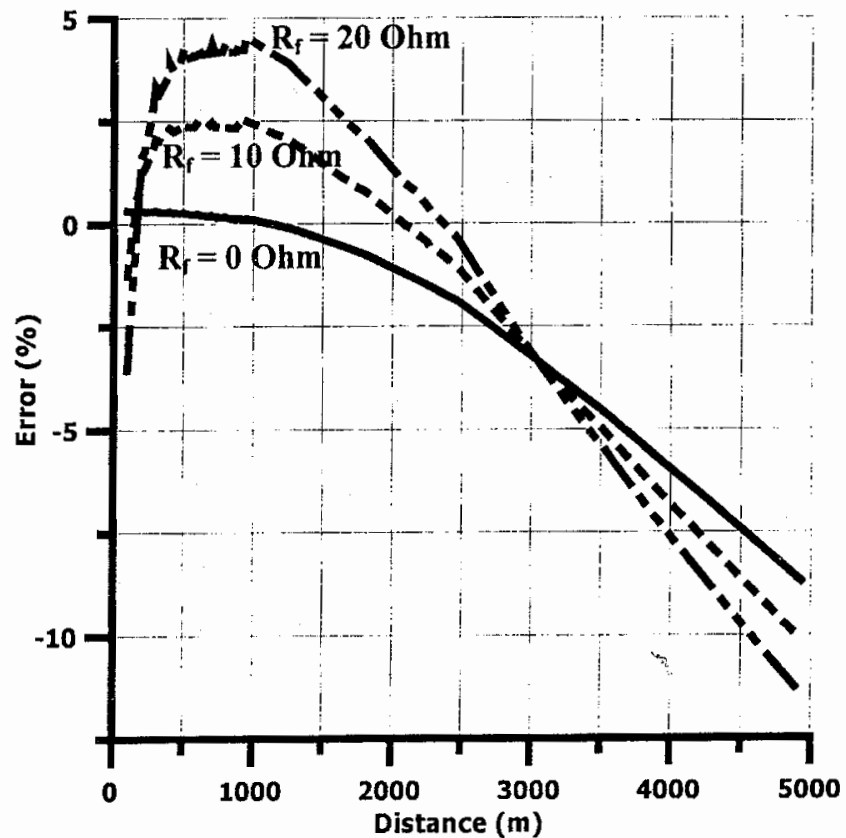

Fig.4b Fault location error along the feeder for line-to-ground fault with different values of fault resistance with the second method 


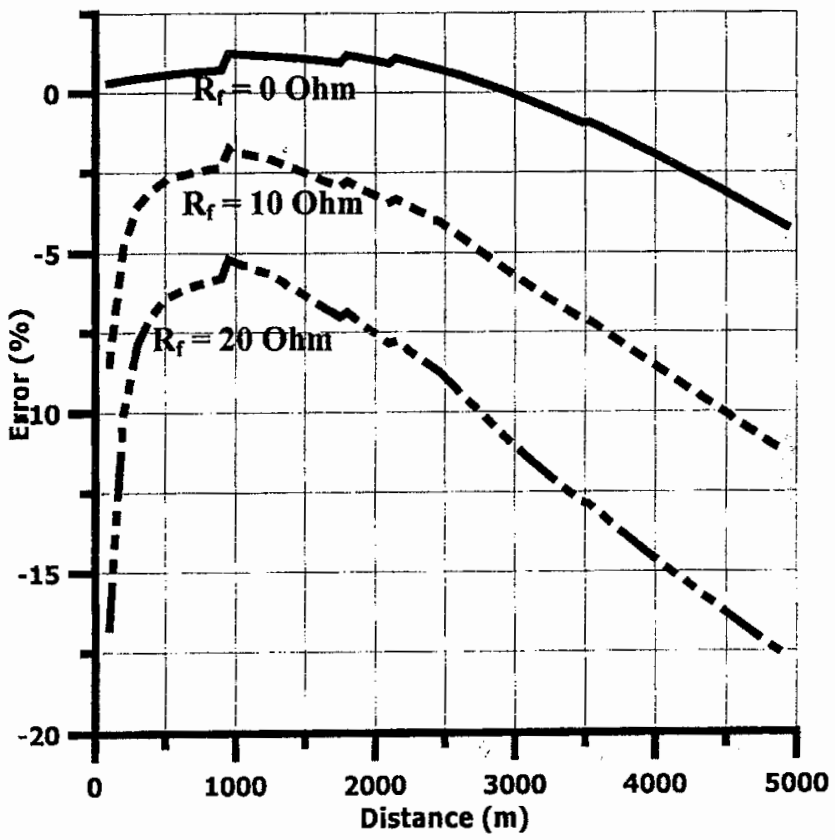

Fig.6a Fault location error along the feeder for line-to-line fault with different values of fault resistance with the third method

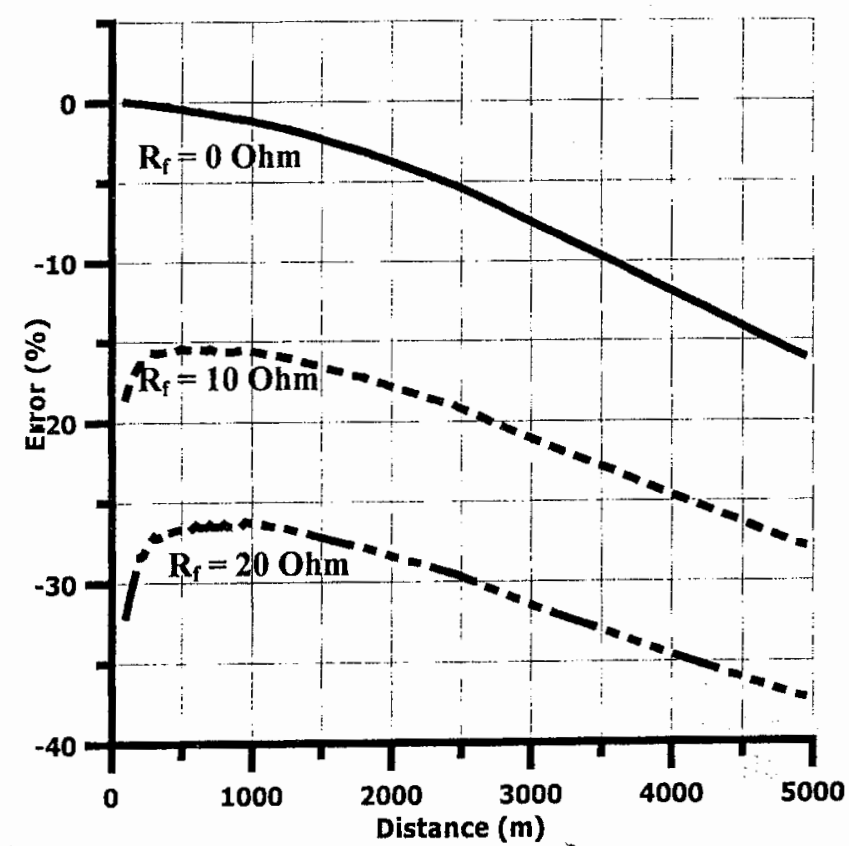

Fig.6b Fault location error along the feeder for line-to-ground fault with different values of fault resistance, with the third method 


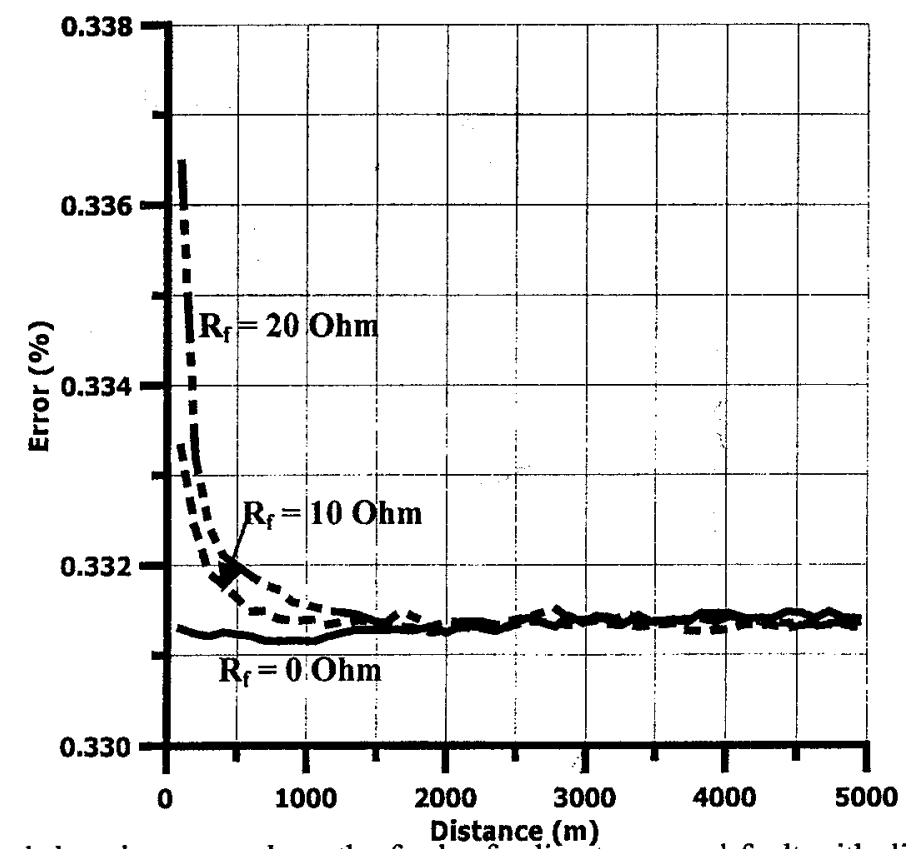

Fig. 8 Fault location error along the feeder for line-to-ground fault with different values of fault resistance, with the fourth method

both line-to-line or line-to-ground fault. This mainly because the effect of load current flow is taken care of. In the first and second method a maximum error at the end of the feeder of about $-8.0 \%$ for line-to-line fault and about $-11.0 \%$ for line-to-ground fault. The third method is the most affected by the type of the fault as it yields a maximum error of about- $11.0 \%$ for line-to-line fault and about $-27.0 \%$ for line-to-ground fault. It can also concluded, increasing $R_{f}$ increases the resultant error. This increase in error is emphasized as the initial load current flow increases. On the other hand decreasing the initial load flow improves the accuracy of fault location determination. The higher accuracy is obtained at no-load, where variation of $R_{f}$ has no effect, with all four methods.

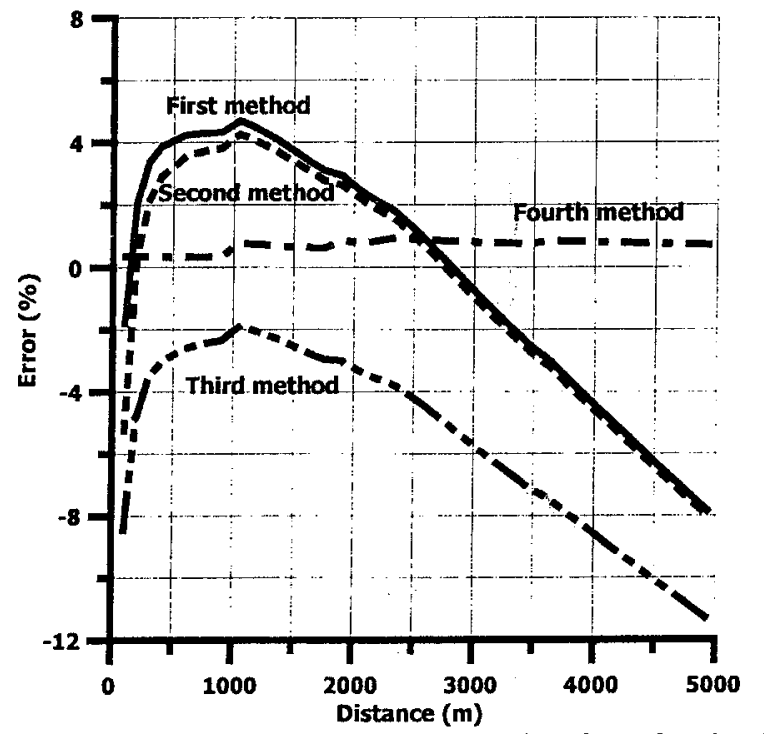

Fig.9a Fault location error along the feeder for line-to-line fault for the four methods with fault resistance $R_{\mathrm{f}}=10 \mathrm{Ohm}$ 


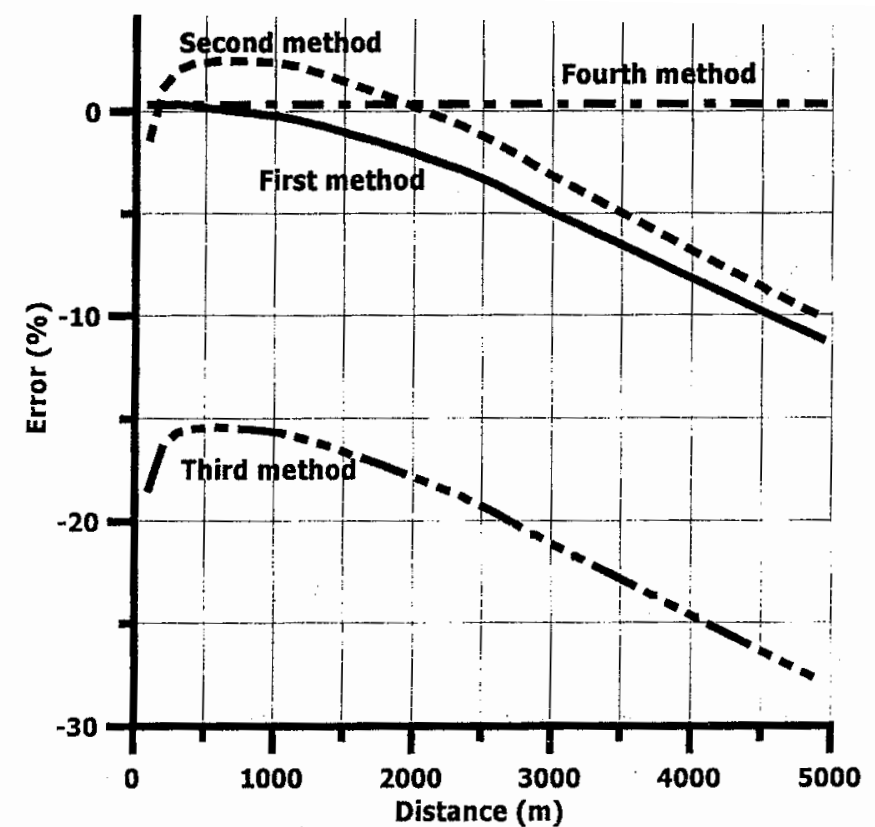

Fig.9b Fault location error along the feeder for line-to-ground fault for the four methods with fault resistance $R_{f}=10 \mathrm{Ohm}$

Response of the algorithm of each of the four methods was examined for a sudden application of line-to-ground fault at 2000 meter from CB1 on the feeder. The results are plotted as shown in Fig.10, in which a steady output is obtained after about $15 \mathrm{msec}$ from the instant of fault application. This response may not be adequate for on-lone fault location determination application, if the fault is detected by instantaneous relays. However, with definite or inverse time relays, this response is quite adequate for most practical applications.

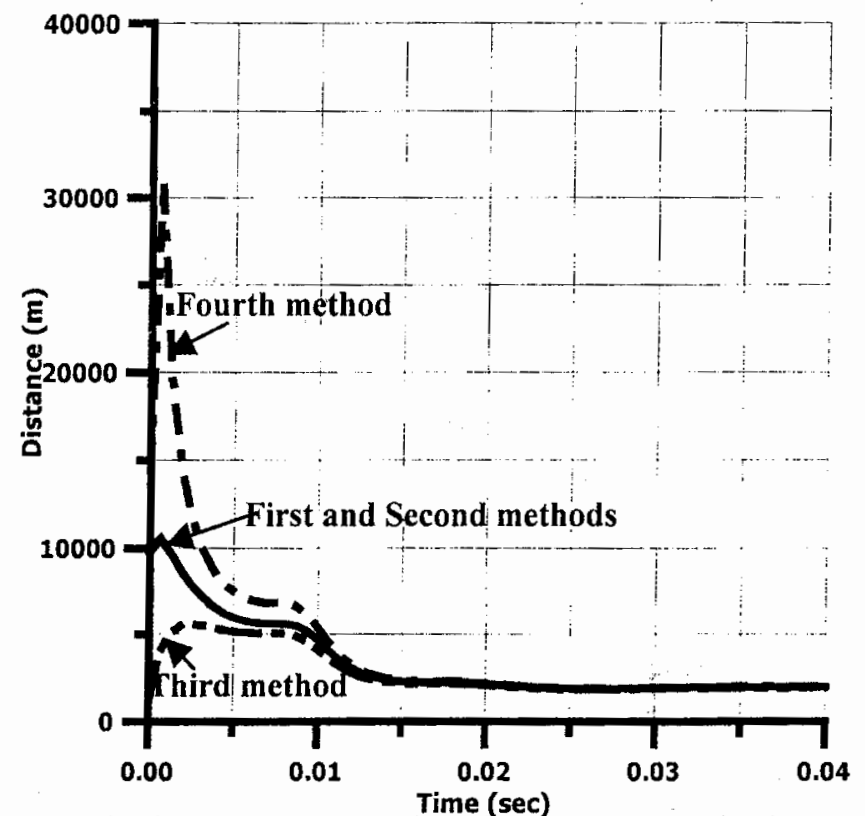

Fig.10 Response of the four method algorithms for a sudden application of line-to-ground fault at $2000 \mathrm{~m}$ from $\mathrm{CB} 1$ 


\section{CONCLUSION}

A comparative study among four fault location methods, used in distribution systems, has been presented. The results have shown that with the first three methods considered, the percentage error of fault location increases as the initial load flow increases and as the fault location moves away from the relaying point. Also increasing of fault resistance have had substantial effect on increasing the error particularly with high values of load current flow. The fourth method has provided the smallest error, amongst the four methods, along the feeder. Providing the initial load flow at various tapping is known. In the first and second methods the line-to-ground fault has yielded an error of about $2.0 \%$ to $4.0 \%$ more than the line-to-line fault at rated full-load flow. The third method, however is substantially affected by the type of fault, as an error difference of about $16.0 \%$ is obtained at full-load. In all four methods a steady output from the fault locator is obtained in about $15 \mathrm{msec}$ from the instant of fault application. This is adequate response for on-line applications. The four methods fail to distinguish between the lateral and main feeders fault locations. However, this distinction may be obtained if the protective devices placement and scenarios of their time-current behavior are known.

\section{REFERENCES}

[1] Adly A. Girgis, Christopher M. Fallon, David L. Lubkeman, "A Fault Location Technique for Rural Distribution Feeders," IEEE Transactions on Industry Applications, Vol. 29, No. 6, November 1993, pp. 1170-1175.

[2] Jun Zhu, David L. Lubkeman, and Adly A. Girgis, "Automated Fault Location and Diagnosis on Electric Power Distribution Feeders," IEEE Transactions on Power Delivery, Vol. 12, No. 2, Appril 1997, pp. 801-809.

[3] T. Takagi et al., "Development of a New Type Fault Locator Using One Terminal Voltage and Current Data," IEEE Trans. Power App. Syst. Vol. PAS-101, No. 8, pp.2892-2898, Aug. 1980.

[4] Harry Lee, Abdul M. Mousa, " GPS Traveling Wave Fault Locator Systems: Investigating into the Anomalous Measurements Related to Lighting Strikes," IEEE Transactions on Power Delivery, Vol. 11, No. 3, July 1996, pp. 1214-1223.

[5] Adly A. Girgis, David G. Hart, William L. Peterson, "A New Fault Location Technique for Two-and Three-Terminal Lines," IEEE Transactions on Power Delivery, Vol. 7, No. 1, January 1992, pp. 98-107.

[6] Zhihong Chen and Jean-Claud Maun, "Artificial Neural Network Approach to Single-Ended for Transmission Lines," IEEE Transactions on Power System, Vol. 15, No. 1, February 2000, pp. 370-375.

[7] Murty V.V.S.Yalla," A Digital Multifunction Protective Relay," IEEE Transactions on Power Delivery, Vol. 7, No. 1, January 1992, pp. 193-200.

\section{APPENDIX}

The parameters of the simulated system are given as:

Source impedance $\left(Z_{\mathrm{s}}\right)$ is 0.05 p.u. on $200 \mathrm{kVA}, 11 \mathrm{kV}$ base.

The main feeder is underground cable of: 


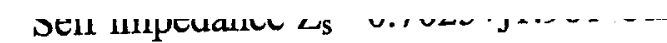

$=0.1324+\mathrm{j} 1.0713 \mathrm{Ohm} / \mathrm{km}$

The distribution transformer ratings and their location distances from CB1 are as given in table1 below:

Table1. Transformer ratings and location

\begin{tabular}{|c|c|c|}
\hline $\begin{array}{c}\text { Transformer } \\
\text { designation }\end{array}$ & Rating kVA & $\begin{array}{c}\text { Distance from } \\
\text { CB1 }(\mathrm{m})\end{array}$ \\
\hline T1P & 250 & 300 \\
\hline T2P & 200 & 500 \\
\hline T3P & 500 & 950 \\
\hline T4P & 500 & 1250 \\
\hline T5P & 250 & 1450 \\
\hline T6P & 500 & 1650 \\
\hline T7P & 300 & 2300 \\
\hline T8P & 500 & 2315 \\
\hline T9P & 300 & 2326 \\
\hline T10P & 200 & 2526 \\
\hline T11P & 500 & 3376 \\
\hline T12P & 300 & 4126 \\
\hline
\end{tabular}


" دراسة مقارنة لطرق تحديد الحطظأ فى نظم التوزيع الإشعاعية " أ.د. عبدالقصود إبر اهيم تعلب ، د. حاتم عبدالسميع دوويش

$$
\begin{aligned}
& \text { قسم المندسة الكهربية - كلية الهندسة - جامعة المنوفية } \\
& \text { أ.د. محمد الخازندار ، أ.د. جهال السعيد ، م. محمد علم } \\
& \text { قسم هنادسة القوى الكهربية - كلية المندسة - جامعة ضنظًا } \\
& \text { ملخص المقالة }
\end{aligned}
$$

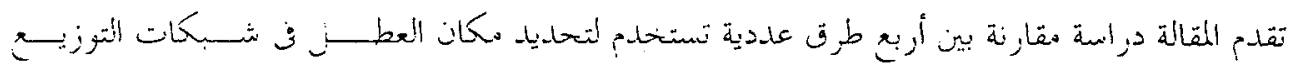

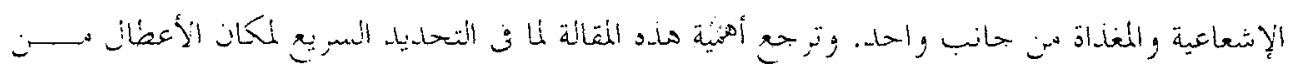

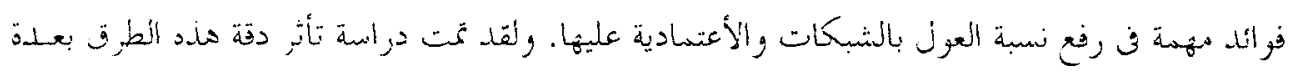

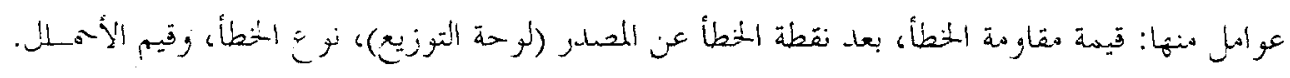

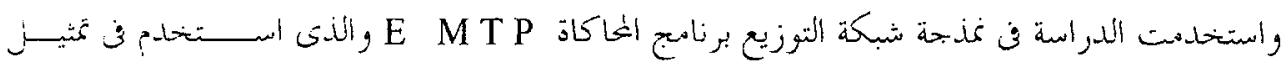

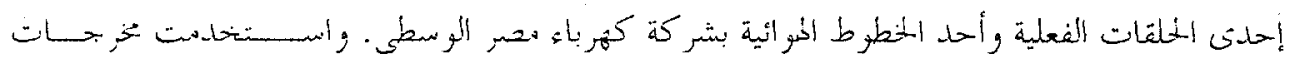

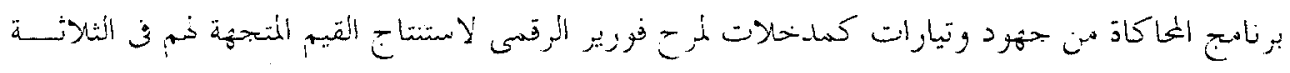

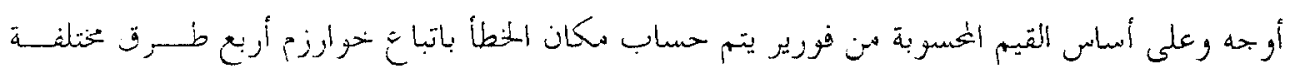

$$
\begin{aligned}
& \text { لاتمام المقارنة. وتشمل هذه الطرق: } \\
& \text { 1- طريقة المعاوقة الظاهرية } \\
& \text { ب- طريقة اكتشاف العطل المديكن } \\
& \text { ب- طر يقة القبارة الغير فعالة } \\
& \text { ؟- طريقة المعاوقة المظاهرية المعلدأة }
\end{aligned}
$$

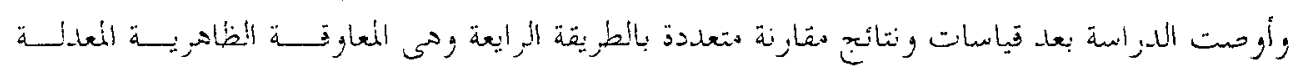

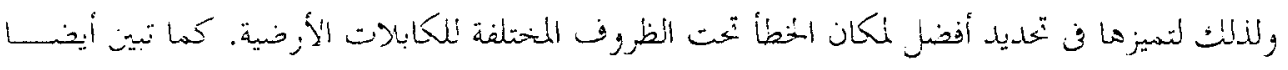

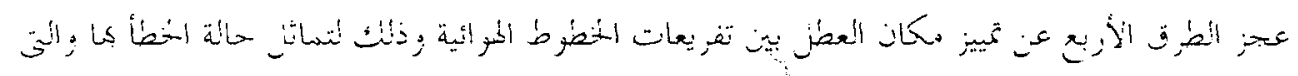

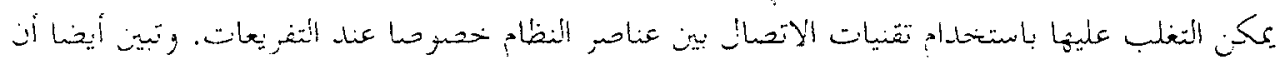

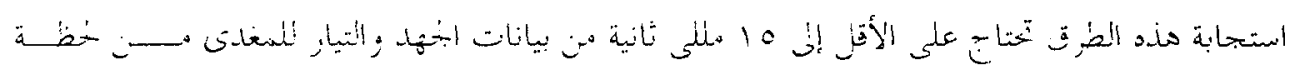

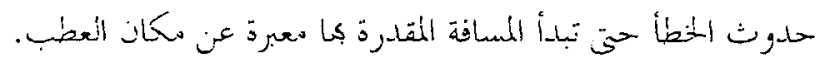

